\title{
Tinjauan Geometrik Jalan Raya \\ Pada Titik-Titik Rawan Kecelakaan (Blackspots) Di Kota Semarang
}

(Studi Kasus : Jalan Prof Hamka, Gombel Lama Dan Kolonel H. Imam Suparto)

Denis Bramedio Herlambang; Rosie Febri Setyadi dan Rudatin Ruktiningsih

Denis.bramedio@gmail.com,rosiefebri_13@ymail.com

Program Studi Teknik Sipil, Fakultas Teknik

Universitas Katolik Soegijapranata, Semarang

\begin{abstract}
This study is based on traffic accidents in Indonesia which increased from year to year, the increase of the accident rate resulted in the loss of material or casualties. Frequent accidents are classified as blackspots (accident-prone points). Then to minimize the blackspot, there is a need to study the safety of traffic more deeply, one of the efforts is to conduct a road geometric review. In the geometric overview of the highway there are horizontal alignments and vertical alignments as the main points of discussion, where horizontal alignments discuss the speed, bend length, stop visibility, side free areas, bend extension and super elevation. While the vertical alinemen discuss about the cleverness, and vertical arch. Analysis of horizontal alignment and vertical alignment based on RSNI 2004 criteria. The results of this study indicate that there are some discussion of horizontal alignment and vertical alignment that is not in accordance with the criteria of RSNI 2004, the discussion includes the length of the curve, the stop visibility, and the side free area for alinemen horizontal, and vertical curvatures and vertical alignments.
\end{abstract}

Keywords: geometric highway, horizontal alignment, vertical alignment.

\begin{abstract}
Abstrak
Penelitian ini berlatar belakang pada kecelakaan lalu lintas di Indonesia yang mengalami peningkatan dari tahun ke tahun, kenaikan tingkat kecelakaan tersebut mengakibatkan meningkatnya kerugian materil ataupun korban jiwa. Ruas jalan yang sering terjadi kecelakaan di klasifikasikan sebagai blackspot (titik rawan kecelakaan). Kemudian untuk meminimalisir blackspot, perlu adanya kajian tentang keselamatan lalu lintas yang lebih mendalam, salah satu upaya tersebut adalah melakukan tinjauan geometrik jalan raya. Dalam tinjauan geometrik jalan raya terdapat alinemen horizontal dan alinemen vertikal sebagai pokok pembahasan utama, dimana alinemen horizontal membahas tentang kecepatan, panjang tikungan, jarak pandang henti, daerah bebas samping, pelebaran tikungan dan super elevasi. Sedangkan alinemen vertikal membahas tentang kelandaian,dan lengkung vertikal. Analisis alinemen horizontal dan alinemen vertikal berdasarkan pada kriteria RSNI 2004. Hasil dari penelitian ini menunjukan bahwa terdapat beberapa pembahasan alinemen horizontal dan alinemen vertikal yang tidak sesuai dengan kriteria RSNI 2004, pembahasan tersebut meliputi panjang tikungan, jarak pandang henti, dan daerah bebas samping untuk alinemen horizontal, serta kelandaian dan lengkung vertikal untuk alinemen vertikal.
\end{abstract}

Kata kunci : geometrik jalan raya, alinemen horizontal, alinemen vertikal 


\section{Pendahuluan}

\subsection{Latar Belakang}

Korban kecelakaan mengalami kerugian materi. Menurut World Health Organization, 2013 secara global kematian akibat kecelakaan mencapai 1,25 juta di dunia, kematian di negara-negara yang memiliki penghasilan rendah dan menengah memiliki tingkat kematian lalu lintas jalan lebih tinggi per 100000 penduduk. Wilayah Afrika memiliki lalu lintas jalan tingkat kematian tertinggi di angka 26,6 persen sedangkan kawasan Eropa memiliki tingkat terendah 9,3 persen.

Menurut peta dalam website World Health Organization, 2013 Indonesia adalah negara urutan ketiga di Asia Tenggara yang memiliki tikat kematian akibat kecelakaan. Di Asia Tenggara hanya lima negara yang memiliki golongan kecelakaan dalam kategori menengah yaitu Philippines 10,5 persen, Laos 14,3 persen, Indonesia 15,3 persen, Timor-Leste 16,6 persen dan Cambodia 17, 4 persen.

Tingginya tingkat kecelakaan di Indonesia memberikan gambaran bahwa kecelakaan lalu lintas di tingkat kota cenderung tinggi. Kota di Indonesia yang memiliki tingkat kecelakaan yang cukup tinggi antara lain Jakarta, Bogor, Depok, Denpasar, Samarinda, Makasar, Medan, Semarang, dan Surabaya.

Kota yang memiliki tingkat kecelakaan yang cukup tinggi tersebut memiliki karakteristik sebagai kota metropolitan.

Kota Semarang sebagai kota metropolitan merupakan Ibukota Propinsi Jawa Tengah dengan beberapa area kecelakaan lalu lintas pada jalan kota, yang masuk kedalam kriteria jalan Nasional (jalan arteri dan jalan kolektor 1) dan jalan Propinsi (jalan kolektor 2 dan jalan kolektor atau lokal 3).

Kecelakaan lalu lintas yang terjadi mengakibatkan daerah tersebut disebut dengan daerah blackspot, blackspot dalam lalu lintas merupakan daerah rawan kecelakaan pada lokasi tunggal, lokasi rawan berbasis ruas dan lokasi rawan berbasis wilayah. Istilah Blackspot memerlukan data pendukung yaitu data kecelakaan lalu lintas yang berada di kepolisian tingkat Kabupaten atau Kota (Korps Lalu Lintas Kepolisian Negara Republik Indonesia, 2011).

Pantauan Suara Merdeka terdapat beberapa jalan di kota Semarang yang merupakan blackspot karena keadaan jalan tersebut merupakan tanjakan ataupun turunan sehingga mengakibatkan kecelakaan lalu lintas, jalan tersebut antara lain adalah jalan Prof. Hamka, jalan Gombel Lama, dan Jalan Kolonel H. Imam Suprapto. Ketiga ruas jalan ini dimasukan kedalam klasifikasi blackspot dikarenakan telah sesuai dengan kriteria blackspot yang ada pada pedoman polisi.

\subsection{Rumusan Masalah}

Kota Semarang sebagai ibukota Provinsi Jawa Tengah merupakan kota dengan kepadatan penduduk sebanyak 1595266 jiwa, banyaknya penduduk dikota semarang mengakibatkan kebutuhan penduduk akan transportasi sangat tinggi (transportasi ke tempat kerja, pendidikan, kesehatan dan hiburan), untuk memenuhi kebutuhan tersebut mengakibatkan masyarakat menjadi konsumtif terhadap kendaraan pribadi.

Kota Semarang dengan luas kota sebesar 373,87 kilometer persegi, memiliki topografi yang cukup lengkap dibandingan kota-kota di pulau Jawa karena kota ini memiliki dua bagian kota yaitu dataran tinggi dan pesisir. Karena dibagi dua bagian, maka kota ini memiliki topografi dengan elevasi yang berbeda berkisar antara 0,5 hingga 300 meter dari permukaan laut. Perbedaan elevasi ini mengakibatkan infrastruktur jalan di Kota Semarang sebagian besar memiliki tanjakan dan turunan. 
Alinemen vertikal maupun alinemen horisontal atau persyaratan pada standar keselamatan dan kenyamanan jalan merupakan kajian dari geometrik jalan yang menjadi salah satu faktor penyebab blackspot.

Dalam hal ini geometrik jalan memiliki peranan penting dalam perencanaan jalan, pembangunan jalan, pengecekan jalan dan perbaikan jalan, hal ini di karenakan geometrik jalan berpengaruh pada bentuk desain jalan.

Apabila desain geometrik jalan tidak sesuai dengan standar keselamatan dan kenyamanan jalan, maka akan berpengaruh pada keselamatan lalu lintas terutama pada kasus kecelakaan lalu lintas sebagai dasar penentuan blackspot.

\subsection{Tujuan penelitian}

Tujuan penelitian ini adalah:

a. Mengetahui kondisi keselamatan lalu lintas di Kota Semarang terutama pada blackspot jalan Prof Hamka, Gombel Lama dan Kolonel H. Imam Suprapto

b. Mengetahui kondisi geometrik Jalan Prof Hamka, Gombel Lama dan Kolonel H. Imam Suprapto

c. Mengetahui upaya penanggulangan keselamatan lalu lintas pada Jalan Prof Hamka, Gombel Lama dan Kolonel H. Imam Suprapto yang telah di laksanakan

d. Mengetahui hubungan antara geometrik dengan keselamatan lalu lintas.

\subsection{Manfaat penelitian}

Manfaat penelitian ini adalah :

a. Memberikan pengetahuan cara penentuan titik blackspot sesuai dengan pedoman

b. Sebagai salah satu masukan bagi pemerintah Kota Semarang untuk membuat ruas jalan Prof. Hamka, Gombel Lama dan Kolonel H. Imam Suprapto menjadi lebih baik.

\subsection{Batasan masalah}

Sebagai Pembatas masalah agar penelitian ini tidak meluas pada aspek pembahasan lain, maka terdapat beberapa batasan masalah pada penelitian ini, yaitu sebagai berikut :

a. Penelitian di laksanakan di Kota Semarang

b. Penelitian di laksanakan pada ruas Jalan Prof. Hamka, Gombel Lama dan Kolonel H. Imam Suprapto

c. Penelitian pada ruas jalan blackspot terpilih merupakan kajian geomatrik.

\section{Tinjauan Putaka}

\subsection{Keselamatan lalu lintas}

Desain jalan yang aman (sesuai dengan prinsip-prinsip geometrik) serta dilengkapi dengan fasilitas perambuan diharapkan dapat menggiring pengemudi untuk merespon kondisi jalan di depannya untuk menghirdarkan manuver atau pergerakan yang tidak diharapkan. menghindarkan perilaku yang ilegal, serta menghindarkan pengemudi dan penggunaan kecepetan yang tidak sesuai dengan desain kecepatan yang ada. Beberapa prinsip dasar perbaikan atau pembuatan desain jalan yang dapat meningkatkan pengharapan pengemudi antara lain melalui (Departemen Pekerjaan Umum, Audit Keselamatan Jalan, 2005) :

a. peningkatan kondisi lingkungan jalan, sehingga pengemudi dapat dengan leluasa untuk menguasai koodisi lingkungan jalan

b. pemasangan rambu peringatan, dan marka yang dapat menuntun pengemudi ketika menuju atau melalui tempattempat berbahaya

c. pengemudi dan pejalan kaki harus dituntun secara konsisten melalui perambuan. marka, serta penjaluran yang cukup jelas terbaca 
d. mempertegas hirarki jalan melalui feature desain guna menggiring lalu lintas mengikuti jalurya

e. mempertegas karakteristik alinemen jalan, bila perlu dilengkapi dengan delineasi (khusus jalan antar kota).

\subsection{Kecelakaan}

Berdasarkan Undang-undang Nomor 22 Tahun 2009 tentang Lalu Lintas dan Angkutan Jalan, mengungkapkan kecelakaan lalu lintas adalah suatu peristiwa di jalan yang tidak diduga dan tidak disengaja yang melibatkan kendaraan dengan atau tanpa pengguna jalan lain yang mengakibatkan korban manusia dan/atau kerugian harta benda.

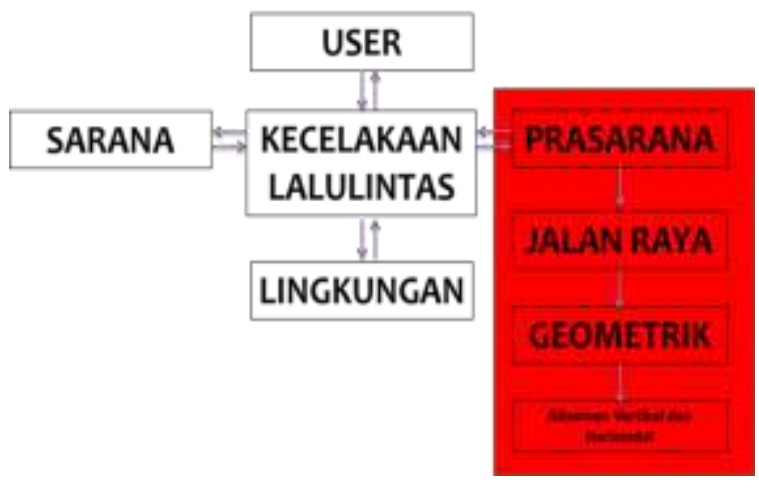

Gambar 1. Hubungan Kecelakaan dengan beberapa aspek Sumber : olahan data pribadi, 2017

\subsection{Penggolongan Kecelakaan Lalu Lintas}

Berdasarkan Undang-undang Nomor 22 Tahun 2009 tentang Lalu lintas dan Angkutan Jalan pada pasal 229, karakteristik kecelakaan lalu lintas dapat dibagi kedalam 3 (tiga) golongan, yaitu:

a. Kecelakaan Lalu Lintas ringan, yaitu kecelakaan yang mengakibatkan kerusakan kendaraan dan/ atau barang.

b. Kecelakaan Lalu Lintas sedang, yaitu kecelakaan yang mengakibatkan luka ringan dan kerusakan kendaraan dan/ atau barang. c. Kecelakaan Lalu Lintas berat, yaitu kecelakaan yang mengakibatkan korban meninggal dunia atau luka berat.

\subsection{Definisi blackspot}

Blackspot atau lokasi rawan kecelakaan merupakan lokasi tunggal yang bersifat spesifik, seperti persimpangan, atau ruas jalan dengan panjang $300-500 \mathrm{~m}$, dengan jumlah total kecelakaan yang memiliki nilai pembobotan kerawanan minimal 30 selama 1 tahun.

Lokasi rawan kecelakaan dibagi menjadi 3 (tiga) bagian (badan penelitian dan pengembangan permukiman dan prasarana wilayah, 2004) dan (direktorat keselamatan transportasi darat, 2007), yaitu :

a. Blackspot atau lokasi rawan kecelakaan berbasis lokasi tunggal merupakan lokasi rawan kecelakaan yang berada di lokasi - lokasi yang spesifik, seperti persimpangan, jembatan, atau ruas jalan dengan panjang $300-500 \mathrm{~m}$.

b. Blacklink atau lokasi rawan kecelakaan berbasis ruas jalan merupakan lokasi rawan kecelakaan yang berada di ruas jalan dengan panjang antara $1-20 \mathrm{~km}$.

c. Blackarea atau lokasi rawan kecelakaan berbasis wilayah merupakan lokasi rawan kecelakaan yang berada di kawasan kawasan atau wilayah tertentu dengan karakteristik yang sama dan tidak hanya terdiri dari 1 (satu) ruas jalan yang sama, misalnya : wilayah kecamatan, wilayah kota atau kabupaten sehingga dapat dilakukan pengaturan dengan menerapkan strategi manajemen lalu lintas. Panjang ruas yang ditentukan untuk menetapkan blackspot atau lokasi rawan kecelakaan berbasis lokasi tunggal sepanjang $1 \mathrm{~km}$.

\subsection{Lokasi blackspot kota Semarang}

Setiap Data blackspot yang telah disesuaikan pada peta kemudian di kumpulkan menjadi satu rangkaian sesuai dengan jalan yang terdapat pada wilayah 
kelurahan, kecamatan, kota, dan provinsi. Penerapan penentuan lokasi blackspot pada Kota Semarang sesuai dengan data Divisi Dikyasa (pendidikan dan rekayasa) Polisi Daerah Semarang hingga tahun 2016 sebagai berikut:

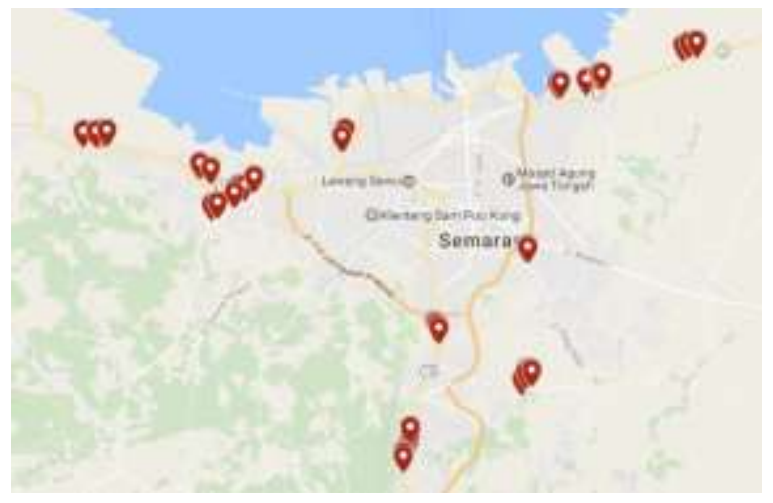

Gambar 2. Peta Blackspot Kota Semarang Sumber : Kepolisian Daerah Jawa Tengah, 2011

\subsection{Klas-Klas Standar Perencanaan Geometrik}

Elemen-elemen utama yang digunakan untuk pengelompokan standar perencanaan geometrik adalah fungsi jalan raya, volume lalulintas rencana (VLLR), dan Kondisi medan (Pekerjaan Umum, 1990) .

a. Volume Lalu Lintas Rencana (VLLR), Tahun Rencana, Koefisien smp

Jika suatu jalan raya akan ditingkatkan, maka diadakan perhitungan lalu lintas, atau bila untuk suatu lokasi baru, dibuat suatu perkiraan. Kemudian nilai-nilai ini diproyeksikan untuk tahun rencana, untuk ditentukaaan sebagai volume lalu lintas rencana (VLLR). VLLR dinyatakan dalam lalu lintas harian ratarata tahunan (LHR tahunan), karena umumnya sulit untuk memprakirakan volume per jam untuk masa depan bagi jalan raya tertentu. Tahun rencana yang direkomdasikan untuk penentuan VLLR adalah 10 sampai 20 tahun mendatang meskipun hal itu tergantung kepada karakteristik dan pentingnya jalan raya tersebut (Pekerjaan Umum, 1990).
VLLR pada spesifikasi ini dinyatakan dalam satuan mobil penumpang (smp) dengan mengesampingkan kendaraan tak bermotor. Angka atau Nilai VLLR menunjukan volume lalu lintas harian untuk kedua jurusan dan dinyatakan dalam mobil penumpang ekivalen. Koefisien - koefisien yang ditunjukan dibawah ini diterapkan sesuai dengan kondisi medan untuk mendapatkan smp ekivalen (Pekerjaan Umum, 1990).

Tabel 1. Koefisien sesuai medan untuk smp ekivalen

\begin{tabular}{l|c|c}
\hline \multicolumn{1}{c|}{ Jenis Kendaraan } & $\begin{array}{c}\text { Daerah Datar } \\
\text { dan perbukitan }\end{array}$ & $\begin{array}{c}\text { Daerah } \\
\text { Pegunungan }\end{array}$ \\
\hline $\begin{array}{l}\text { sepeda motor, } \\
\text { sedan, jeep, station } \\
\text { wagon }\end{array}$ & 1.0 & 1.0 \\
\hline $\begin{array}{l}\text { Pick up, bis ukuran } \\
\text { kecil, truck ringan }\end{array}$ & 2.0 & 2.5 \\
\hline $\begin{array}{l}\text { Bis, truk dua as } \\
\text { Truk bersumbu tiga, } \\
\text { trailer }\end{array}$ & 3.0 & 4.0 \\
\hline
\end{tabular}

Sumber : RSNI Geometri Jalan Perkotaan, 2004

Dalam menghitung VLR, kendaraan tidak bermotor seperti sepeda, becak, cikar tidak diperhitungkan sebab pengoprasiannya jauh berbeda dibandingkan kendaraan bermotor dan pengaruhnya atas lalu lintas kendaraan bermotor berubah tergantung volume lalu lintas kendaraan bermotor itu sendiri. Tidak selayaknya untuk beranggapan bahwa suatu kondisi perencanaan geometrik akan sesuai bagi kendaraan bermotor maupun tidak bermotor.

b. Kecepatan Rencana $\left(V_{R}\right)$

Kecepatan yang dipilih untuk mengikat komponen perencanaan geometri jalan dinyatakan dalam kilometer per jam (km atau jam). $V_{R}$ untuk suatu ruas jalan dengan kelas dan fungsi yang sama, dianggap sama sepanjang ruas jalan tersebut, $V_{R}$ untuk masing - masing fungsi jalan ditetapakan sesuai table 2 . 
Untuk kondisi lingkungan dan atau medan yang sulit, $V_{R}$ suatu bagian jalan dalam suatu ruas jalan dapat diturunkan, dengan syarat bahwa penururnan tersebut tidak boleh lebih dari 20 kilometer per jam (km /jam).

Tabel 2 Kecepatan Rencana $\left(V_{R}\right)$ sesuai klasifikasi jalan di kawasan perkotaan

\begin{tabular}{c|l|c}
\hline No & \multicolumn{1}{|c|}{ Fungsi Jalan } & $\begin{array}{c}\text { Kecepatan } \\
\text { Rencana, } V_{R} \\
(\mathrm{~km} / \mathrm{jam})\end{array}$ \\
\hline 1 & Arteri Primer & $50-100$ \\
\hline 2 & Kolektor Primer & $40-80$ \\
\hline 3 & Arteri Sekunder & $50-80$ \\
\hline 4 & Kolektor Sekunder & $30-50$ \\
\hline 5 & Lokal Sekunder & $30-50$ \\
\hline
\end{tabular}

Sumber : RSNI Geometri Jalan Perkotaan, 2004

c. Klasifikasi kondisi medan

Untuk membatasi biaya pembangunan jalan maka standar harus disesuaikan dengan keadaan topografi medan diabgi atas 3 jenis yang dibedakan oleh besarnya kemiringan medan dalam arah yang kira-kira tegak luruh as jalan raya. Pengelompokan medan dan kemiringan medan yang bersangkutan adalah sebagai berikut (Pekerjaan Umum, 1990):

Tabel 1. Klasifikasi kondisi medan

\begin{tabular}{l|l}
\hline Jenis Medan & $\begin{array}{l}\text { Rata-rata kemiringan } \\
\text { melintang }\end{array}$ \\
\hline Datar (D) & $0-9,9 \%$ \\
\hline Perbukitan (PB) & $10-24,9 \%$ \\
\hline Pegunungan (PG) & $>25 \%$ \\
\hline
\end{tabular}

Sumber : RSNI Geometri Jalan Perkotaan, 2004

Kondisi medan ruas jalan yang diproyeksikan harus diperkirakan untuk keseluruhan panjang jalan. Perubahan medan untuk bagian kecil ruas tersebut dapat diabaikan.

d. Potongan melintang untuk lebar Jalur

a) Lebar jalur ditentukan oleh jumlah dan labar lajur serta bahu jalan. Tabel
2.4 menetapkan ukuran lebar lajur dan bahu jalan sesuai dengan kelas jalannya

b) Lebar jalur minimum adalah 4,5 m, memungkinkan 2 kendaraan dengan lebar maksimum 2,1 $\mathrm{m}$ saling berpapasan. Papas an 2 kendaraan lebar maksimum 2,5 m yang terjadi sewaktu - waktu dapat memanfaatkan bahu jalan.

Tabel 3. Lebar lajur jalan dan bahu jalan

\begin{tabular}{l|l|l|l|l|l|l}
\hline \multirow{2}{*}{$\begin{array}{l}\text { Kelas } \\
\text { Jalan }\end{array}$} & \multicolumn{2}{|c|}{$\begin{array}{c}\text { Lebar Jalur (m) } \\
\text { kan }\end{array}$} & $\begin{array}{c}\text { Mini } \\
\text { mum }\end{array}$ & \multicolumn{2}{|c}{ Lebar Bahu Sebelah Luar (m) } \\
\cline { 4 - 7 } & $\begin{array}{c}\text { Disaran } \\
\text { kan }\end{array}$ & $\begin{array}{c}\text { Mini } \\
\text { mum }\end{array}$ & $\begin{array}{c}\text { Disaran } \\
\text { kan }\end{array}$ & $\begin{array}{c}\text { Mini } \\
\text { mum }\end{array}$ \\
\hline I & 3,60 & 3,50 & 2,50 & 2,00 & 1,00 & 0,50 \\
\hline II & 3,60 & 3,00 & 2,50 & 2,00 & 0,50 & 0,25 \\
\hline III A & 3,60 & 2,75 & 2,50 & 2,00 & 0,50 & 0,25 \\
\hline III B & 3,60 & 2,75 & 2,50 & 2,00 & 0,50 & 0,25 \\
\hline III C & 3,60 & $*)$ & 1,50 & 0,50 & 0,50 & 0,25 \\
\hline
\end{tabular}

*)= jalan 1 -jalur- 2 , lebar $4,50 \mathrm{~m}$

Sumber : RSNI Geometri Jalan Perkotaan, 2004

Pada jalan arteri, jalur kendaraan tidak bermotor di sarankan dipisah dengan jalur kendaraan bermotor, bila banyak kendaraan lambat, jalur boleh lebih lebar. Lebar bahu jalan sebelah dalam pada median yang diturunkan atau datar minimum sebesar $0,50 \mathrm{~m}$.

e. Jarak pandang

Jarak pandang henti $\left(\mathrm{S}_{\mathrm{s}}\right)$ terdiri dari dua elemen jarak, yaitu:

a) jarak awal reaksi $\left(\mathrm{S}_{\mathrm{r}}\right)$ adalah jarak pergerakan kendaraan sejak pengemudi melihat suatu halangan yang menyebabken ia harus berhenti sampai saat pengemudi menginjak rem: dan

b) jarak awal pengereman $\left(S_{b}\right)$ adalah jarak pergerakan kendaraan sejak 
pengemudi mengijak rem sampai dengan kendaraan tersebut berhenti.

Ss dalam satuan meter, dapat dihitung dengen rumus (1) jarak pandang (AASHTO, 2001):

$$
\begin{aligned}
S_{S}= & 0,278 \times V_{R} \times T \\
& +0,039 \frac{V_{R}^{2}}{a} \ldots \ldots \ldots .
\end{aligned}
$$

dengan pengertian:

$\mathrm{V}_{\mathrm{R}}=$ kecepatan rencana $(\mathrm{km} / \mathrm{jam})$

$\mathrm{T}=$ waktu reaksi, ditetapkan 2,5 detik

$\mathrm{a}=$ tingkat perlambatan $\left(\right.$ meter/detik $\left.{ }^{2}\right)$. ditetapkan 3,4 meter/detik ${ }^{2}$

Tabel 5 berisi $S_{\mathrm{s}}$ minimum yang dihitung berdasarkan rumus di atas dengan pembulatan-pembulatan untuk berbagal $V_{R}$ Setiap bagian jalan harus memenuhi $\mathrm{S}_{\mathrm{S}}$.

Tabel 5. Jarak Pandang Henti

\begin{tabular}{c|c|c|c|c|c|c|c|c}
\hline $\mathrm{V}_{\mathrm{R}(\mathrm{km} / \mathrm{jam})}$ & 100 & 90 & 80 & 70 & 60 & 50 & 40 & 30 \\
\hline $\mathrm{S}_{\mathrm{S} \text { minimum (m) }}$ & 185 & 160 & 130 & 105 & 85 & 65 & 50 & 35 \\
\hline
\end{tabular}

sumber : RSNI Geometri Jalan Perkotaan, 2004

f. Daerah bebas samping di tikungan Daerah bebas samping dimaksudkan untuk memberikan kemudahan pandangan di tikunqan dengan membebaskan obyekobyek penghalang sejauh $\mathrm{M}(\mathrm{m})$, diukur dan garis tegah lajur dalam sampai obyek penghalang pandangan sehingga persyaratan $\mathrm{S}_{\mathrm{s}}$, dipenuhi (gambar 3 ).

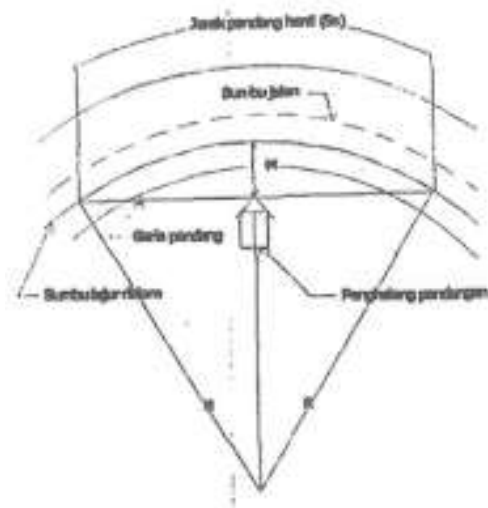

Gambar 3. Diagram ilustrasi komponen untuk menentukan jarak pandang horizontal (daerah bebas samping)

sumber : RSNI Geometri Jalan Perkotaan, 2004

Daerah bebas samping di tikungan dihitung berdasarkan rumus 2.2 daerah bebas samping (AASHTO, 2001) sebagai berikut:

$$
M=R\left[1-\operatorname{Cos}\left(\frac{28,65 S_{S}}{R}\right)\right]
$$

Dengan pengertian :

$$
\begin{aligned}
\mathrm{R}= & \text { Jari-jari tikungan }(\mathrm{m}) \\
\mathrm{S}_{\mathrm{S}}= & \text { Jarak pandang henti }(\mathrm{m}) \\
\mathrm{M}= & \text { jarak yang diukur dari garis tengah } \\
& \text { lajur dalam sampai obyek } \\
& \text { penghalang pandangan }(\mathrm{m})
\end{aligned}
$$

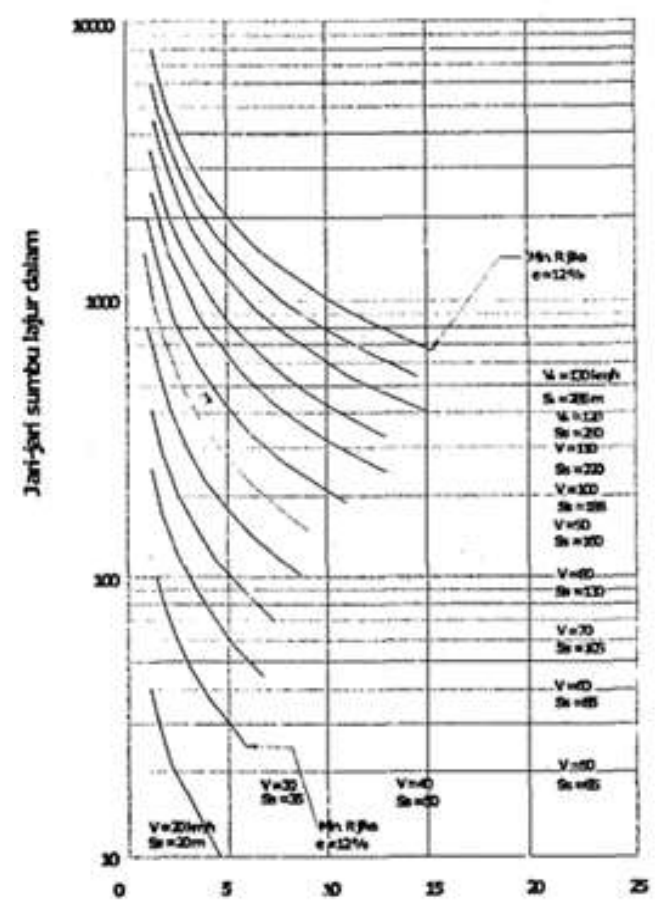

Gambar 4. menyajikan nilai $M$ yang dihitung menggunakan rumus di atas.

Grafik tersebut dapat dipakai untuk menetapkan M. sumber : RSNI Geometri Jalan Perkotaan, 2004

Pada kenyataannya, Nilai $M$ yang ditunjukkan oleh garis putus-putus dalam grafik pada Gambar 4 tersebut tidak digunakan. 


\section{Metode Penelitian}

\subsection{Populasi dan Sampel}

Objek atau subjek yang sesuai denga kriteria tertentu yang telah ditentukan oleh peneliti untuk selanjutnya digunakan riset penelitian (pridana dan Muis, 2009).

Dalam penelitian ini populasi adalah blackspot di Kota Semarang berdasar Suara Merdeka, 12 Januari 2017, Geometri Jalan Sulit Dikompromikan ruas jalan di Semarang yang rawan kecelakaan adalah J1 Prof Hamka, Jl walisongo KM 12, Jl Perintis Kemerdekaan-Pudak Payung, Jl Gombel Lama, J1 Setiabudi, Jl Kedungmundu, J1 Kolonel H. Imam Suprapto, J1 Brigjen Sudiarto, J1 Arteri Yosudarso dan Jl Majapahit.

Tabel 6. Tabel kesamaan karatkteristik blackspot

\begin{tabular}{|c|c|c|c|c|c|}
\hline \multirow[b]{2}{*}{ No } & \multirow[b]{2}{*}{ Ruas Jalan } & \multicolumn{4}{|c|}{ Karakteristik } \\
\hline & & $\begin{array}{c}\text { Alineme } \\
n \\
\text { Vertikal }\end{array}$ & $\begin{array}{c}\text { Alinemen } \\
\text { Horizonta } \\
1\end{array}$ & $\begin{array}{c}\text { Blackspo } \\
t\end{array}$ & $\begin{array}{l}\text { Ruas } \\
\text { Jalan } \\
\text { Kota }\end{array}$ \\
\hline 1 & Jl Prof Hamka & $\checkmark$ & $\checkmark$ & $\checkmark$ & $\checkmark$ \\
\hline 2 & Jl Walisongo KM 12 & & $\checkmark$ & $\checkmark$ & $\checkmark$ \\
\hline 3 & $\begin{array}{l}\text { Jl Perintis Kemerdekaan- } \\
\text { Pudak Payung }\end{array}$ & $\checkmark$ & & $\checkmark$ & $\checkmark$ \\
\hline 4 & Jl Gombel Lama & $\checkmark$ & $\checkmark$ & $\checkmark$ & $\checkmark$ \\
\hline 5 & Jl Setiabudi & & $\checkmark$ & $\checkmark$ & $\checkmark$ \\
\hline 6 & Jl Kedungmundu & & $\checkmark$ & $\checkmark$ & $\checkmark$ \\
\hline 7 & Jl Kolonel H Imam Suparto & $\checkmark$ & $\checkmark$ & $\checkmark$ & $\checkmark$ \\
\hline 8 & Jl Brigjen Sudiarto & & $\checkmark$ & $\checkmark$ & $\checkmark$ \\
\hline 9 & Jl Arteri Yosudarso & & $\checkmark$ & $\checkmark$ & $\checkmark$ \\
\hline 10 & Jl Majapahit & & $\checkmark$ & $\checkmark$ & $\checkmark$ \\
\hline
\end{tabular}

Sumber : Suara Merdeka, 12 januari 2017, Semarang Dikelilingi "Jalur Tengkorak"

\subsection{Objek Penelitian}

Pada penelitian ini mengambil objek blackspot di Kota Semarang. Lokasi yang terpilih dalam penelitian ini terdapat di tiga ruas jalan yang tiap ruasnya akan diteliti maksimal sepanjang 1 kilometer, sebagai berikut :

a. Ruas jalan Prof Hamka

b. Ruas jalan Gombel Lama

c. Ruas jalan Kolonel H. Imam Suprapto

\subsection{Pengumpulan Data}

\subsubsection{Data Primer}

Data primer diperoleh dengan melakukan pengamatan langsung (orisinal) di lapangan
(Nazir, 2013). Data primer yang diperoleh pada saat melakukan pengamatan adalah:
a. Kecepatan user
b. Lebar jalan
c. Panjang jalan
d. Elevasi jalan
e. Jarak bebas samping
f. Fasilitas Jalan

\subsubsection{Data Sekuder}

Data sekunder adalah data yang mendukung data primer berupa informasi yang tidak bersumber dari pengamatan langsung secara resmi seperti data yang diperoleh dari instansi penyelidik blackspot atau didapat melalui literarure dan datadata yang berhubungan dengan penelitian (Nazir, 2013). Data sekunder yang digunakan berasal dari dua instansi, yang pertama merupakan instansi Polisi Daerah Semarang dengan data sebagai berikut:

a. Polisi Daerah Jawa Tengah

a) Lokasi blackspot

b. Instansi Kedua merupakan Dinas Pekerjaan Umum Dikjen Bina Marga dengan data sebagai berikut:

a) Jarak pandang rencana

b) Kecepatan rencana

c) Keadaan Jalan Rencana

\subsubsection{Instrumen Penelitian}

Instrumen penelitian adalah suatu metode yang digunakan sebagai tolak ukur dalam penelitian agar dapat diolah dengan teori yang ada dan mencapai tujuan penelitian (Sugiyono, 2012). Dalam penelitian ini, instrument yang digunakan adalah :

a. Tinjauan Lapangan

Data ini berupa gambaran langsung yang didapat pada saat pengamatan langsung untuk mengetahui dengan jelas lokasi penelitian. Pengamatan dilalukan dengan mengendarai kendaraan dengan kecepatan rendah $(<20 \mathrm{~km}$ atau jam) atau melakukan penyusuran dengan berjalan kaki 
dengan mengamati sepanjang ruas jalan Prof Hamka, Gombel Lama dan Tanjakan Sigar Bencah).

b. Pengamatan dengan alat ukur Alat yang digunakan dalam pengamatan ini adalah Total station. Data yang didapat berupa data lebar jalan, beda tinggi sepanjang ruas jalan dan besar sudut tikungan.

c. Dokumentasi keselamatan ruas jalan

perlengkapan

Perekaman kondisi secara visual dengan kamera untuk menggambarkan lokasi penelitian..

\section{Hasil Penelitian}

\subsection{Prof Hamka}

Tabel 7. Rekap Alinemen Horisontal

\begin{tabular}{|c|c|c|c|c|c|}
\hline \multirow{2}{*}{ No } & \multirow{2}{*}{ Indikator } & \multicolumn{3}{|c|}{ Blackspot } & \multirow{2}{*}{ Ket } \\
\hline & & 1 & 2 & 3 & \\
\hline 1. & STA & $\begin{array}{c}00+050 \\
\text { s.d. } \\
00+200\end{array}$ & $\begin{array}{c}00+250 \\
\text { s.d. } \\
00+350\end{array}$ & $\begin{array}{c}00+400 \\
\text { s.d. } \\
00+500\end{array}$ & \\
\hline 2. & $\begin{array}{l}\text { Kriteria Kecepatan } \\
\text { RSNI } 2004\end{array}$ & $\begin{array}{l}30 \mathrm{~km} / \\
\mathrm{jam} \\
\mathrm{s.d} . \\
50 \mathrm{~km} / \\
\mathrm{jam}\end{array}$ & $\begin{array}{l}30 \mathrm{~km} / \\
\mathrm{jam} \\
\mathrm{s.d} . \\
50 \mathrm{~km} / \\
\mathrm{jam}\end{array}$ & $\begin{array}{c}30 \\
\mathrm{~km} / \mathrm{jam} \\
\mathrm{s.d.} \\
50 \mathrm{~km} / \\
\text { jam }\end{array}$ & \\
\hline 3. & $\begin{array}{l}\text { Kriteria Kecepatan } \\
\text { Dinas Pekerjaan } \\
\text { Umum Kota } \\
\text { semarang }\end{array}$ & $\begin{array}{l}40 \mathrm{~km} / \\
\mathrm{jam} \\
\mathrm{s.d.} \\
50 \mathrm{~km} / \\
\text { jam }\end{array}$ & $\begin{array}{l}40 \mathrm{~km} / \\
\mathrm{jam} \\
\mathrm{s.d.} \\
50 \mathrm{~km} / \\
\mathrm{jam}\end{array}$ & $\begin{array}{l}40 \mathrm{~km} / \\
\mathrm{jam} \\
\mathrm{s.d} . \\
50 \mathrm{~km} / \\
\mathrm{jam}\end{array}$ & \\
\hline 4. & $\begin{array}{l}\text { Kecepatan } \\
\text { Perhitungan } \\
\text { Eksisting (Rumus } \\
\text { 2.4) }\end{array}$ & $\begin{array}{c}50,14 \mathrm{~km} / \\
\mathrm{jam}\end{array}$ & $\begin{array}{c}50,14 \mathrm{~km} / \\
\text { jam }\end{array}$ & $\begin{array}{c}50,14 \mathrm{~km} / \\
\mathrm{jam}\end{array}$ & Sesuai \\
\hline 5. & $\begin{array}{l}\text { Kriteria Panjang } \\
\text { RSNI } 2004\end{array}$ & 85 meter & 85 meter & 85 meter & \\
\hline 6. & $\begin{array}{l}\text { Panjang } \\
\text { Perhitungan } \\
\text { (Rumus 2.3) }\end{array}$ & $\begin{array}{l}58,12 \\
\text { meter }\end{array}$ & $\begin{array}{l}21,98 \\
\text { meter }\end{array}$ & $\begin{array}{l}58,12 \\
\text { meter }\end{array}$ & $\begin{array}{l}\text { Tidak } \\
\text { Sesuai }\end{array}$ \\
\hline 7. & $\begin{array}{l}\text { Kriteria Jarak } \\
\text { Pandang Henti } \\
\text { RSNI } 2004\end{array}$ & 65 meter & 65 meter & 65 meter & \\
\hline 8. & $\begin{array}{l}\text { Perhitungan Jarak } \\
\text { Pandang Henti } \\
\text { (Rumus 2.1) }\end{array}$ & $\begin{array}{l}63,42 \\
\text { meter }\end{array}$ & $\begin{array}{l}63,42 \\
\text { meter }\end{array}$ & $\begin{array}{l}63,42 \\
\text { meter }\end{array}$ & $\begin{array}{l}\text { Tidak } \\
\text { Sesuai }\end{array}$ \\
\hline 9. & $\begin{array}{l}\text { Perhitungan Daerah } \\
\text { Bebas Samping } \\
\text { (Rumus 2.2) }\end{array}$ & $\begin{array}{l}5,53 \\
\text { meter }\end{array}$ & $\begin{array}{c}5,53 \\
\text { meter }\end{array}$ & $\begin{array}{c}5,53 \\
\text { meter }\end{array}$ & \\
\hline 10. & $\begin{array}{l}\text { Survei Lapangan } \\
\text { Daerah Bebas } \\
\text { Samping }\end{array}$ & $\begin{array}{l}6,25 \\
\text { meter }\end{array}$ & $\begin{array}{l}6,80 \\
\text { meter }\end{array}$ & $\begin{array}{l}9,30 \\
\text { meter }\end{array}$ & Sesuai \\
\hline 11. & $\begin{array}{l}\text { Kriteria Pelebaran } \\
\text { Tikungan RSNI } \\
2004\end{array}$ & 0,5 meter & 0,5 meter & 0,5 meter & \\
\hline 12. & $\begin{array}{l}\text { Perhitungan } \\
\text { Pelebaran } \\
\text { Tikungan (Rumus } \\
\text { 2.7) }\end{array}$ & 0 meter & 0 meter & 0 meter & $\begin{array}{l}\text { Tidak } \\
\text { Sesuai }\end{array}$ \\
\hline
\end{tabular}

Sumber: Olahan data primer, 2017
Tabel 8. Rekap Alinemen Vertikal

\begin{tabular}{|c|c|c|c|c|c|}
\hline \multirow[t]{2}{*}{ No } & \multirow[t]{2}{*}{ Indikator } & \multicolumn{3}{|c|}{ Blackspot } & \multirow{2}{*}{ Ket } \\
\hline & & A & $B$ & C & \\
\hline 1. & STA & $\begin{array}{c}00+100 \\
\text { s.d. } \\
00+250\end{array}$ & $\begin{array}{c}00+400 \\
\text { s.d. } \\
00+500\end{array}$ & $\begin{array}{c}00+400 \\
\text { s.d. } \\
00+500\end{array}$ & \\
\hline 2. & $\begin{array}{l}\text { Kecepatan } \\
\text { Ketentuan Dinas } \\
\text { Pekerjaan Umum } \\
\text { Kota Semarang }\end{array}$ & $\begin{array}{c}50 \mathrm{~km} / \\
\mathrm{jam}\end{array}$ & $\begin{array}{c}50 \mathrm{~km} / \\
\mathrm{jam}\end{array}$ & $\begin{array}{c}50 \mathrm{~km} / \\
\mathrm{jam}\end{array}$ & \\
\hline 3. & $\begin{array}{l}\text { Kecepatan } \\
\text { Kendaraan Roda } \\
2 \text { (Sepeda Motor) }\end{array}$ & $\begin{array}{c}20 \mathrm{~km} / \\
\text { jam s.d. } \\
50 \mathrm{~km} / \\
\mathrm{jam}\end{array}$ & $\begin{array}{c}20 \mathrm{~km} / \\
\mathrm{jam} \mathrm{s.d.} \\
50 \mathrm{~km} / \\
\mathrm{jam}\end{array}$ & $\begin{array}{c}20 \mathrm{~km} / \\
\mathrm{jam} \mathrm{s.d.} \\
50 \mathrm{~km} / \\
\mathrm{jam}\end{array}$ & \\
\hline 4. & $\begin{array}{l}\text { Kecepatan } \\
\text { Kendaraan Roda } \\
4 \text { (Mobil) }\end{array}$ & $\begin{array}{c}20 \mathrm{~km} / \\
\mathrm{jam} \mathrm{s.d} . \\
50 \mathrm{~km} / \\
\mathrm{jam}\end{array}$ & $\begin{array}{c}20 \mathrm{~km} / \\
\mathrm{jam} \mathrm{s.d.} \\
50 \mathrm{~km} / \\
\mathrm{jam}\end{array}$ & $\begin{array}{c}20 \mathrm{~km} / \\
\mathrm{jam} \mathrm{s.d.} \\
50 \mathrm{~km} / \\
\mathrm{jam}\end{array}$ & \\
\hline 5. & $\begin{array}{l}\text { Kecepatan } \\
\text { Kendaraan Roda } \\
4 \text { (Truk) }\end{array}$ & $\begin{array}{c}20 \mathrm{~km} / \\
\mathrm{jam} \mathrm{s.d} . \\
50 \mathrm{~km} / \\
\mathrm{jam}\end{array}$ & $\begin{array}{c}20 \mathrm{~km} / \\
\mathrm{jam} \mathrm{s.d.} \\
50 \mathrm{~km} / \\
\mathrm{jam}\end{array}$ & $\begin{array}{l}20 \mathrm{~km} / \\
\text { jam s.d. } \\
50 \mathrm{~km} / \\
\text { jam }\end{array}$ & \\
\hline 6. & $\begin{array}{l}\text { Lengkung } \\
\text { Vertkal }\end{array}$ & 100 meter & 100 meter & 100 meter & \\
\hline 7. & $\begin{array}{l}\text { S Ketentuan } \\
\text { RSNI } 2004\end{array}$ & 65 meter & 65 meter & 65 meter & \\
\hline 8. & S Perhitunan & $\begin{array}{l}61,77 \\
\text { meter }\end{array}$ & $\begin{array}{c}135,54 \\
\text { meter }\end{array}$ & $\begin{array}{l}49,35 \\
\text { meter }\end{array}$ & $\begin{array}{r}\mathrm{A}=\text { Tidak } \\
\quad \text { Sesuai } \\
\mathrm{B}=\text { Sesuai } \\
\mathrm{C}=\text { Tidak } \\
\text { Sesuai }\end{array}$ \\
\hline
\end{tabular}

Sumber: Olahan data primer, 2017

4.2 Gombel Lama

Tabel 9. Rekap Alinemen Horisontal

\begin{tabular}{|c|c|c|c|c|}
\hline \multirow{2}{*}{ No } & \multirow{2}{*}{ Indikator } & \multicolumn{2}{|c|}{ Blackspot } & \multirow{2}{*}{ Ket } \\
\hline & & 1 & 2 & \\
\hline 1. & STA & $\begin{array}{l}00+050 \\
\text { s.d. } \\
00+200\end{array}$ & $\begin{array}{l}00+250 \\
\quad \text { s.d. } \\
00+350\end{array}$ & \\
\hline 2. & $\begin{array}{l}\text { Kriteria Kecepatan } \\
\text { RSNI } 2004\end{array}$ & $\begin{array}{l}30 \mathrm{~km} / \mathrm{jam} \\
\quad \mathrm{s} . \mathrm{d} . \\
50 \mathrm{~km} / \mathrm{jam}\end{array}$ & $\begin{array}{l}30 \mathrm{~km} / \mathrm{jam} \\
\text { s.d. } \\
50 \mathrm{~km} / \mathrm{jam}\end{array}$ & \\
\hline 3. & $\begin{array}{l}\text { Kriteria Kecepatan } \\
\text { Dinas Pekerjaan } \\
\text { Umum Kota } \\
\text { semarang }\end{array}$ & $\begin{array}{c}40 \mathrm{~km} / \mathrm{jam} \\
\text { s.d. } \\
50 \mathrm{~km} / \mathrm{jam}\end{array}$ & $\begin{array}{c}40 \mathrm{~km} / \mathrm{jam} \\
\text { s.d. } \\
50 \mathrm{~km} / \mathrm{jam}\end{array}$ & \\
\hline 4. & $\begin{array}{l}\text { Kecepatan } \\
\text { Perhitungan } \\
\text { Eksisting (Rumus } \\
\text { 2.4) } \\
\end{array}$ & $50,14 \mathrm{~km} / \mathrm{jam}$ & $50,14 \mathrm{~km} / \mathrm{jam}$ & Sesuai \\
\hline 5. & $\begin{array}{l}\text { Kriteria Panjang } \\
\text { RSNI } 2004\end{array}$ & $85 \mathrm{~m}$ & $85 \mathrm{~m}$ & \\
\hline 6. & $\begin{array}{l}\text { Panjang } \\
\text { Perhitungan } \\
\text { (Rumus 2.3) }\end{array}$ & $58,12 \mathrm{~m}$ & $21,98 \mathrm{~m}$ & Tidak Sesuai \\
\hline 7. & $\begin{array}{l}\text { Kriteria Jarak } \\
\text { Pandang Henti } \\
\text { RSNI 2004 }\end{array}$ & $65 \mathrm{~m}$ & $65 \mathrm{~m}$ & \\
\hline 8. & $\begin{array}{l}\text { Perhitungan Jarak } \\
\text { Pandang Henti } \\
\text { (Rumus 2.1) }\end{array}$ & $63,42 \mathrm{~m}$ & $63,42 \mathrm{~m}$ & Tidak Sesuai \\
\hline 9. & $\begin{array}{l}\text { Perhitungan } \\
\text { Daerah Bebas } \\
\text { Samping (Rumus } \\
2.2 \text { ) }\end{array}$ & $5,53 \mathrm{~m}$ & $5,53 \mathrm{~m}$ & \\
\hline 10. & $\begin{array}{l}\text { Survei Lapangan } \\
\text { Daerah Bebas } \\
\text { Samping }\end{array}$ & $6,25 \mathrm{~m}$ & $6,80 \mathrm{~m}$ & Sesuai \\
\hline 11. & $\begin{array}{l}\text { Kriteria Pelebaran } \\
\text { Tikungan RSNI } \\
2004\end{array}$ & $0,5 \mathrm{~m}$ & $0,5 \mathrm{~m}$ & \\
\hline 12. & $\begin{array}{l}\text { Perhitungan } \\
\text { Pelebaran } \\
\text { Tikungan (Rumus } \\
\text { 2.7) }\end{array}$ & $0 \mathrm{~m}$ & $0 \mathrm{~m}$ & Tidak Sesuai \\
\hline
\end{tabular}

Sumber : Olahan data primer, 2017 
Tabel 10. Rekap Alinemen Vertikal

\begin{tabular}{|c|l|c|c|}
\hline No & \multicolumn{1}{|c|}{ Indikator } & Blackspot A & Ket \\
\hline 1. & STA & $\begin{array}{c}00+100 \\
\text { s.d. } \\
00+250\end{array}$ & \\
\hline 2. & $\begin{array}{l}\text { Kecepatan Ketentuan Dinas } \\
\text { Pekerjaan Umum Kota Semarang }\end{array}$ & $50 \mathrm{~km} / \mathrm{jam}$ & \\
\hline 3. & $\begin{array}{l}\text { Kecepatan Kendaraan Roda } 2 \\
\text { (Sepeda Motor) }\end{array}$ & $\begin{array}{c}20 \mathrm{~km} / \mathrm{jam} \mathrm{s.d.} 50 \\
\mathrm{~km} / \mathrm{jam}\end{array}$ & \\
\hline 4. & $\begin{array}{l}\text { Kecepatan Kendaraan Roda } 4 \\
\text { (Mobil) }\end{array}$ & $\begin{array}{c}20 \mathrm{~km} / \mathrm{jam} \mathrm{s.d.} \text {. } 50 \\
\mathrm{~km} / \mathrm{jam}\end{array}$ & \\
\hline 5. & $\begin{array}{l}\text { Kecepatan Kendaraan Roda } 4 \\
\text { (Truk) }\end{array}$ & $\begin{array}{c}20 \mathrm{~km} / \mathrm{jam} \mathrm{s.d.} 50 \\
\mathrm{~km} / \mathrm{jam}\end{array}$ & \\
\hline 6. & Lengkung Vertikal & $100 \mathrm{~meter}$ & \\
\hline 7. & S Ketentuan RSNI 2004 & $65 \mathrm{~meter}$ & \\
\hline 8. & S Perhitunan & 49,35 meter & $\begin{array}{c}\text { Tidak } \\
\text { Sesuai }\end{array}$ \\
\hline
\end{tabular}

Sumber: Olahan data primer, 2017

\subsection{Kolonel H Imam Suparto}

Tabel 11. Rekap Alinemen Horisontal

\begin{tabular}{|c|c|c|c|c|c|c|c|c|}
\hline \multirow{2}{*}{ No } & \multirow{2}{*}{ Indikator } & \multicolumn{6}{|c|}{ Blackspot } & \multirow{2}{*}{ Ket } \\
\hline & & 1 & 2 & 3 & 4 & 5 & 6 & \\
\hline 1. & STA & $\begin{array}{c}00+ \\
050 \\
\text { s.d. } \\
00+ \\
150 \\
\end{array}$ & $\begin{array}{c}00+ \\
150 \\
\text { s.d. } \\
00+ \\
200 \\
\end{array}$ & $\begin{array}{c}00+ \\
200 \\
\text { s.d. } \\
00+ \\
250 \\
\end{array}$ & $\begin{array}{c}00+ \\
250 \\
\text { s.d. } \\
00+ \\
350 \\
\end{array}$ & $\begin{array}{c}00+ \\
350 \\
\text { s.d. } \\
00+ \\
450 \\
\end{array}$ & $\begin{array}{c}00+ \\
450 \\
\text { s.d. } \\
00+ \\
550 \\
\end{array}$ & \\
\hline 2. & $\begin{array}{l}\text { Kriteria } \\
\text { Kecepatan } \\
\text { RSNI 2004 }\end{array}$ & $\begin{array}{c}30 \\
\mathrm{~km} / \\
\mathrm{jam} \\
\mathrm{s.d} . \\
50 \\
\mathrm{~km} / \\
\mathrm{jam} \\
\end{array}$ & $\begin{array}{c}30 \\
\mathrm{~km} / \\
\mathrm{jam} \\
\text { s.d. } \\
50 \\
\mathrm{~km} / \\
\mathrm{jam}\end{array}$ & $\begin{array}{c}30 \\
\mathrm{~km} / \\
\mathrm{jam} \\
\mathrm{s.d} . \\
50 \\
\mathrm{~km} / \\
\mathrm{jam} \\
\end{array}$ & $\begin{array}{c}30 \\
\mathrm{~km} / \\
\mathrm{jam} \\
\text { s.d. } \\
50 \\
\mathrm{~km} / \\
\mathrm{jam}\end{array}$ & $\begin{array}{c}30 \\
\mathrm{~km} / \\
\mathrm{jam} \\
\mathrm{s.d} . \\
50 \\
\mathrm{~km} / \\
\mathrm{jam}\end{array}$ & $\begin{array}{c}30 \\
\mathrm{~km} / \\
\mathrm{jam} \\
\mathrm{s.d} . \\
50 \\
\mathrm{~km} / \\
\mathrm{jam} \\
\end{array}$ & \\
\hline 3. & $\begin{array}{l}\text { Kriteria } \\
\text { Kecepatan } \\
\text { Dinas } \\
\text { Pekerjaan } \\
\text { Umum Kota } \\
\text { semarang }\end{array}$ & $\begin{array}{c}40 \\
\mathrm{~km} / \\
\mathrm{jam} \\
\text { s.d. } \\
50 \\
\mathrm{~km} / \\
\mathrm{jam}\end{array}$ & $\begin{array}{l}40 \\
\mathrm{~km} / \\
\mathrm{jam} \\
\text { s.d. } \\
50 \\
\mathrm{~km} / \\
\mathrm{jam}\end{array}$ & $\begin{array}{c}40 \\
\mathrm{~km} / \\
\mathrm{jam} \\
\mathrm{s.d} . \\
50 \\
\mathrm{~km} / \\
\mathrm{jam}\end{array}$ & $\begin{array}{l}40 \\
\mathrm{~km} / \\
\mathrm{jam} \\
\text { s.d. } \\
50 \\
\mathrm{~km} / \\
\mathrm{jam}\end{array}$ & $\begin{array}{c}40 \\
\mathrm{~km} / \\
\mathrm{jam} \\
\mathrm{s.d} . \\
50 \\
\mathrm{~km} / \\
\mathrm{jam}\end{array}$ & $\begin{array}{c}40 \\
\mathrm{~km} / \\
\mathrm{jam} \\
\mathrm{s.d} . \\
50 \\
\mathrm{~km} / \\
\mathrm{jam} \\
\end{array}$ & \\
\hline 4. & $\begin{array}{l}\text { Kecepatan } \\
\text { Perhitungan } \\
\text { Eksisting } \\
\text { (Rumus 2.4) }\end{array}$ & $\begin{array}{c}40,08 \\
\mathrm{~km} / \\
\mathrm{jam}\end{array}$ & $\begin{array}{c}50,14 \\
\mathrm{~km} / \\
\mathrm{jam}\end{array}$ & $\begin{array}{c}40,08 \\
\mathrm{~km} / \\
\mathrm{jam}\end{array}$ & $\begin{array}{c}50,14 \\
\mathrm{~km} / \\
\mathrm{jam}\end{array}$ & $\begin{array}{c}40,08 \\
\mathrm{~km} / \\
\mathrm{jam}\end{array}$ & $\begin{array}{c}31,63 \\
\mathrm{~km} / \\
\mathrm{jam}\end{array}$ & $\mathrm{S}$ \\
\hline 5. & $\begin{array}{l}\text { Kriteria } \\
\text { Panjang RSNI } \\
2004\end{array}$ & $\begin{array}{c}85 \\
\text { meter }\end{array}$ & $\begin{array}{c}85 \\
\text { meter }\end{array}$ & $\begin{array}{c}85 \\
\text { meter }\end{array}$ & $\begin{array}{c}85 \\
\text { meter }\end{array}$ & $\begin{array}{c}85 \\
\text { meter }\end{array}$ & $\begin{array}{c}85 \\
\text { meter }\end{array}$ & \\
\hline 6. & $\begin{array}{l}\text { Panjang } \\
\text { Perhitungan } \\
\text { (Rumus 2.3) }\end{array}$ & $\begin{array}{l}47,86 \\
\text { meter }\end{array}$ & $\begin{array}{l}43,07 \\
\text { meter }\end{array}$ & $\begin{array}{l}32,59 \\
\text { meter }\end{array}$ & $\begin{array}{l}59,94 \\
\text { meter }\end{array}$ & $\begin{array}{l}52,84 \\
\text { meter }\end{array}$ & $\begin{array}{l}36,19 \\
\text { meter }\end{array}$ & TS \\
\hline 7. & $\begin{array}{l}\text { Kriteria Jarak } \\
\text { Pandang Henti } \\
\text { RSNI } 2004\end{array}$ & $\begin{array}{c}50 \\
\text { meter }\end{array}$ & $\begin{array}{c}65 \\
\text { meter }\end{array}$ & $\begin{array}{c}50 \\
\text { meter }\end{array}$ & $\begin{array}{c}65 \\
\text { meter }\end{array}$ & $\begin{array}{c}65 \\
\text { meter }\end{array}$ & $\begin{array}{c}35 \\
\text { meter }\end{array}$ & \\
\hline 8. & $\begin{array}{l}\text { Perhitungan } \\
\text { Jarak Pandang } \\
\text { Henti (Rumus } \\
2.1 \text { ) } \\
\end{array}$ & $\begin{array}{l}46,15 \\
\text { meter }\end{array}$ & $\begin{array}{l}63,42 \\
\text { meter }\end{array}$ & $\begin{array}{l}46,15 \\
\text { meter }\end{array}$ & $\begin{array}{l}63,42 \\
\text { meter }\end{array}$ & $\begin{array}{l}63,42 \\
\text { meter }\end{array}$ & $\begin{array}{c}31,17 \\
3 \\
\text { meter }\end{array}$ & TS \\
\hline 9. & $\begin{array}{l}\text { Perhitungan } \\
\text { Daerah Bebas } \\
\text { Samping } \\
\text { (Rumus 2.2) } \\
\end{array}$ & $\begin{array}{l}4,77 \\
\text { meter }\end{array}$ & $\begin{array}{l}5,53 \\
\text { meter }\end{array}$ & $\begin{array}{l}4,77 \\
\text { meter }\end{array}$ & $\begin{array}{l}5,53 \\
\text { meter }\end{array}$ & $\begin{array}{c}5,53 \\
\text { meter }\end{array}$ & $\begin{array}{l}3,959 \\
\text { meter }\end{array}$ & \\
\hline 10. & $\begin{array}{l}\text { Survei } \\
\text { Lapangan } \\
\text { Daerah Bebas } \\
\text { Samping } \\
\end{array}$ & $\begin{array}{c}3,70 \\
\text { meter }\end{array}$ & $\begin{array}{c}3,83 \\
\text { meter }\end{array}$ & $\begin{array}{l}3,50 \\
\text { meter }\end{array}$ & $\begin{array}{l}3,82 \\
\text { meter }\end{array}$ & $\begin{array}{c}3,75 \\
\text { meter }\end{array}$ & $\begin{array}{c}3,65 \\
\text { meter }\end{array}$ & TS \\
\hline 11. & $\begin{array}{l}\text { Kriteria } \\
\text { Pelebaran } \\
\text { Tikungan } \\
\text { RSNI 2004 }\end{array}$ & $\begin{array}{l}0,50 \\
\text { meter }\end{array}$ & $\begin{array}{l}0,50 \\
\text { meter }\end{array}$ & $\begin{array}{l}0,50 \\
\text { meter }\end{array}$ & $\begin{array}{l}0,50 \\
\text { meter }\end{array}$ & $\begin{array}{c}0,50 \\
\text { meter }\end{array}$ & $\begin{array}{c}0,50 \\
\text { meter }\end{array}$ & \\
\hline 12. & $\begin{array}{l}\text { Perhitungan } \\
\text { Pelebaran } \\
\text { Tikungan } \\
\text { (Rumus 2.7) }\end{array}$ & $\begin{array}{c}0,20 \\
\text { meter }\end{array}$ & $\begin{array}{c}0 \\
\text { meter }\end{array}$ & $\begin{array}{c}0 \\
\text { meter }\end{array}$ & $\begin{array}{c}0,5 \\
\text { meter }\end{array}$ & $\begin{array}{c}0,50 \\
\text { meter }\end{array}$ & $\begin{array}{c}3,00 \\
\text { meter }\end{array}$ & $\mathrm{S}$ \\
\hline $\begin{array}{l}\mathrm{K} \\
\mathrm{T} \\
\mathrm{S}\end{array}$ & $\begin{array}{l}\text { erangan : } \\
=\text { Tidak Sesuai } \\
=\text { Sesuai }\end{array}$ & & & & & & & \\
\hline
\end{tabular}

Sumber: Olahan data primer, 2017

\section{Kesimpulan dan Saran \\ 5.1 Kesimpulan}

\subsubsection{Ruas jalan Prof Hamka}

Pada ruas jalan Prof Hamka memiliki 3 lokasi rawan kecelakaan untuk kategori alinemen horizontal dan 3 lokasi rawan kecelakaan untuk kategori alinemen vertikal, sebagai berikut :

1. Pada blackspot 1 dengan panjang tikungan 58,12 meter (standar 65 meter) dan jarak pandang 63,42 meter (standar 65 meter).

2. Pada blackspot 2 dengan panjang tikungan 21,98 meter (standar 85 meter) dan jarak pandang 63,42 meter (standar 65 meter).

3. Pada blackspot 3 dengan panjang tikungan 58,12 meter (standar 85 meter) dan jarak pandang 63,42 meter (standar 65 meter).

4. Pada blackspot A dengan jarak pandang henti 61,77 meter (standar 85 meter).

5. Pada blackspot $\mathrm{C}$ dengan jarak pandang henti 65meter (standar 65 meter).

\subsubsection{Ruas jalan Gombel Lama}

ruas jalan Gombel Lama memiliki 2 lokasi rawan kecelakaan untuk kategori alinemen horizontal dan 1 lokasi rawan kecelakaan untuk kategori alinemen vertikal, sebagai berikut :

1. Pada blackspot 1 dengan panjang tikungan 77,73 meter (standar 85 meter) dan jarak pandang henti 63,42 meter (standar 65 meter).

2. Pada blackspot 2 dengan panjang tikungan 46,77 meter (standar 85 meter), jarak pandang henti 63,42 meter (standar 65 meter) dan daerah bebas samping 4,75 (standar 5,53 meter). 


\subsubsection{Ruas jalan Kolonel $H$. ImamSuparto}

ruas jalan Kolonel $H$ Imam Suparto memiliki 6 lokasi rawan kecelakaan untuk kategori alinemen horizontal dan 2 lokasi rawan kecelakaan untuk kategori alinemen vertikal.

1. Pada blackspot 1 dengan panjang tikungan 47,86 meter (standar 65 meter), jarak pandang henti 46,15 meter (standar 50 meter), daerah bebas samping 3,70 (standar 4,77 meter) dan pelebaran jalan 0,2 meter (standar 0,5 meter).

2. Pada blackspot 2 dengan panjang tikungan 43,07 meter (standar 85 meter), jarak pandang henti 63,42 meter (standar 65 meter), daerah bebas samping 3,82 (standar 5,53 meter) dan pelebaran jalan 0,0 meter (standar 0,5 meter).

3. Pada blackspot 3 dengan panjang tikungan 32,59 meter (standar 65 meter), jarak pandang henti 46,152 meter (standar 50 meter), daerah bebas samping 3,50 (standar 5,53 meter) dan pelebaran jalan 0,0 meter (standar 0,5 meter).

4. Pada blackspot 4 dengan panjang tikungan 47,86 meter (standar 65 meter), jarak pandang henti 63,42 meter (standar 65 meter) dan daerah bebas samping 3,82 (standar 5,53 meter).

5. Pada blackspot 5 dengan panjang tikungan 36,19 meter (standar 55 meter), jarak pandang henti 31,173 meter (standar 35 meter) dan daerah bebas samping 3,65 (standar 4,959 meter).

\subsubsection{Blackspot berdasar alinemen horizontal dan alinemen vertikal}

Ketiga ruas jalan prof Hamka, Gombel lama dan Kolonel $\mathrm{H}$ Imam Suparto memiliki lokasi paling rawan kecelakaan karena tergolong rawan kecelakaan dalam alinemen hoririontal dan alinemen vertikal, yaitu :

a. Prof Hamka pada STA 0+100 sampai $0+200$ dan STA $0+250$ sampai $0+300$

b. Gombel Lama pada STA $0+100$ sampai STA $0+150$

c. Kolonel H Imam Suparto pada STA $0+50$ sampai $0+250$

\subsection{Saran}

\subsubsection{Ruas jalan Prof Hamka}

Untuk ruas jalan Prof Hamka diseluruh lokasi rawan kecelakaan memerlukan perbaikan untuk memberi perambuan kecepatan ideal sebesar $40 \mathrm{~km} / \mathrm{jam}$, memberi perambuan sebagai jalan rawan kecelakaan, memberikan perambuan untuk memperlambat kecepatan, memberikan kamera pengawas (CCTV) guna memaksimalkan ketaatan user terhadap rambu-rambu lalu lintas, memberikan monumen peringatan jalan rawan kecelakaan, memberikan rumble strip ada jalur yang mengarah ke turunan sebelum lokasi dengan jarak 35 meter, memberi fasilitas jembatan timbang, memperpanjang tikungan sesuai perhitungan analisa, mengurangi kelandaian dan memperbaiki lengkungan vertikal agar mencapai jarak henti sesuai perhitungan analisa.

\subsubsection{Ruas jalan Gombel Lama}

Untuk ruas jalan Gombel Lama diseluruh lokasi rawan kecelakaan memerlukan perbaikan untuk memberi perambuan kecepatan ideal sebesar $40 \mathrm{~km} /$ jam, memberi perambuan sebagai jalan rawan kecelakaan, memberikan perambuan untuk memperlambat kecepatan, memberikan kamera pengawas (CCTV) guna memaksimalkan ketaatan user terhadap rambu-rambu lalu lintas, memberikan monumen peringatan jalan rawan kecelakaan, memberikan rumble strip ada jalur yang mengarah ke turunan 
sebelum lokasi dengan jarak 35 meter, memperpanjang tikungan sesuai perhitungan analisa, mengurangi kelandaian dan memperbaiki lengkungan vertikal agar mencapai jarak henti sesuai perhitungan analisa.

\subsubsection{Ruas jalan Kolonel H Imam Suparto}

Untuk ruas jalan Kolonel $\mathrm{H}$ Imam Suparto diseluruh lokasi rawan kecelakaan memerlukan perbaikan untuk memberi perambuan kecepatan ideal sebesar $40 \mathrm{~km} /$ jam dan kurang dari $30 \mathrm{~km} /$ jam untuk tikungan terakhir, memberi perambuan sebagai jalan rawan kecelakaan, memberikan perambuan untuk memperlambat kecepatan, memberikan kamera pengawas (CCTV) guna memaksimalkan ketaatan user terhadap rambu-rambu lalu lintas, memberikan monumen peringatan jalan rawan kecelakaan, memberikan rumble strip ada jalur yang mengarah ke turunan sebelum lokasi dengan jarak 35 meter, memperpanjang tikungan sesuai perhitungan analisa, mengurangi kelandaian dan memperbaiki lengkungan vertikal agar mencapai jarak henti sesuai perhitungan analisa.

Berikut merupakan sara-saran dalam penelitian "Tinjauan Geometrik Jalan Raya Pada Titik-Titik Rawan Kecelakaan (Blackspots) Di Kota Semarang (Studi Kasus : Jalan Prof Hamka, Gombel Lama dan Kolonel H. Imam Suparto)", serta diharapkan dapat melakukan penelitian lebih lanjut terhadap titik titik rawan kecalakan (blackspot) di kota Semarang, terutama pada ruas jalan Prof Hamka, Gombel Lama, dan Kolonel H. Imam Suparto.

\section{Daftar Pustaka}

Departemen Pekerjaan Umum. (1990).

Tata Cara Perencanaan Geometrik

Jalan Antarkota. Jakarta:

Departemen Pekerjaan Umum.

Departemen Pekerjaan Umum. (2004). Standar Geometrik Jalan Perkotaan RSNI. Jakarta : Departemen Pekerjaan Umum.

Kepolisian daerah jawa tengah. (2011). Penentuan dan Pengkajian Blackspot bagi Kepolisian Negara Republik Indonesia. Semarang: Modul Internal Korps Lalu Lintas Kepolisian Negara Republik Indonesia.

Nazir. (2013). Metodologi penelitian. Bogor: Ghalia Indonesia

Republik Indonesia. (2009). UndangUndang Nomor 22 Tentang Lalu Lintas Dan Angkutan Jalan, Sekretariat Negara. Jakarta. terdapat pada

http://www.hukumonline.com/pusatd ata/downloadfile/lt4a604fffd43d3/par ent/lt4a604fcfd406d

Sugiyono. (2013). Metode penelitian Kuantitatif Kualitatif Dan $R \& D$. Jakarta : Alfabeta

World Health Organization. Tingkat Kecelakaan di Dunia.2013. www.who.int di akses pada 04 Februari 2017 Pukul 11.35 WIB

Suara Merdeka. (2017). Semarang dikelilingi jalur Tengkorak. Harian Suara Merdeka 12 Januari 2017: Semarang 